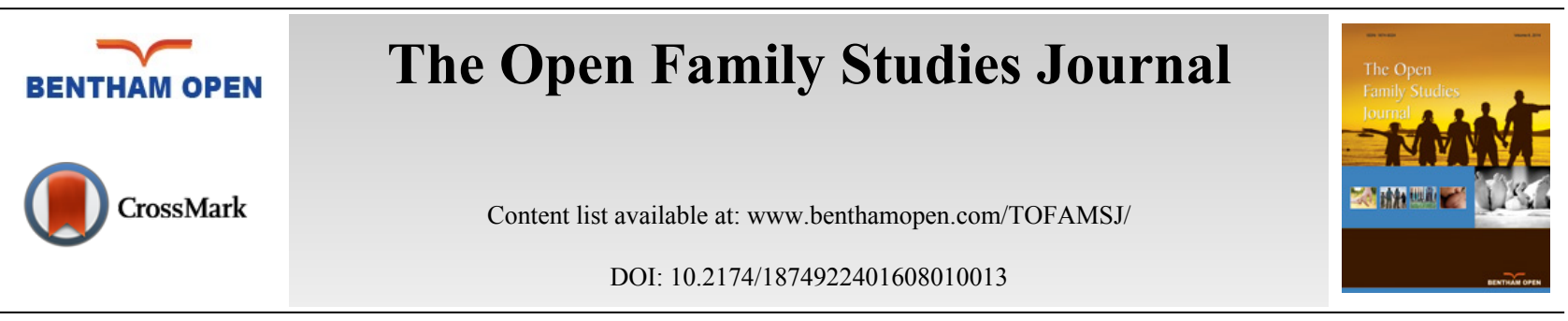

\title{
State Ideology and Female School Enrollment in Iran
}

\author{
${\text { Akbar Aghajanian }{ }^{1, *}, \text { Vaida Thompson }{ }^{2} \text { and Ali A. Moqadas }}^{3}$ \\ ${ }^{I}$ Department of Sociology, Fayetteville State University, Fayetteville, NC 28301, United States \\ ${ }^{2}$ Department of Psychology, University of North Carolina, Chapel Hill, NC 27514, United States \\ ${ }^{3}$ Department of Sociology, Shiraz University, Shiraz, Iran
}

\begin{abstract}
There are two forces that drive attitudes and behaviors in Iran. Strong Islamic, religious traditions that continue to dominate the culture exist in the presence of an emerging pattern of developmental idealism. This idealism, seen first in western societies, is associated with beliefs about and a striving toward such modern attributes as individualism, autonomy of children, nuclear families, equality between women and men, and planned family formation. It is thought that diffusion of this idealism occurs over time and cannot be fully controlled by traditional institutions and conservative governments. Because religious traditions in Iran have been most defined and restricted for females, we reasoned that an important and strong indicator of evidence of diffusion would be increases in female school enrollment. To explore these changes, we examined public record data for the period between 1976 and 2006. The data demonstrated clear advancements in education for women. The strong educational attainment of women during the period of study is parallel to findings in other areas, particularly in the realms of increase in age of marriage, control over reproductive behaviors including birth timing and family size, and are thus supportive of a strong trend toward developmental idealism [1 - 9]. This trend was facilitated by extensive expansion of access to educational institutions by the government.
\end{abstract}

Keywords: Development Idealism, education, Gender Inequality, Iran, Islamic government, Women.

\section{INTRODUCTION}

There is an extensive and growing literature in both social science and history concerning the status and destiny of women in Muslim countries, a general assumption being that the religious tradition of Islam inherently condemns women to an irrevocably lower status than that of men [2 - 5]. It is, however, erroneous to assume that processes that operate in various Muslim countries are invariant, i.e., religious practices, social-cultural systems, and forms of government are largely identical across countries. Factors external and even inconsistent with religious tenets can differentially affect any culture. Here, we consider one such factor "the expansion of development idealism" [6 - 8]. The set of values labeled developmental idealism emerged first in western societies and is associated with beliefs about and a striving toward such modern attributes as individualism, autonomy of children, nuclear families, equality between women and men, and planned family formation. The diffusion of this idealism tends to occur over time and to be relatively impervious to traditional institutions and conservative governments. Furthermore, the emergence of the developmental ideal varies across societies and communitiesas it is impacted by the flow and volume of information exchange that comes about through migration and travel, expansion of computer networks and access to internet, and digital media. The importance of the spread of developmental idealism is particularly relevant today because beliefs and values are increasingly seen as influencing family and demographic behavior. In fact, developmental idealism contradicts important elements of the idealized family morality historically existing in Iran [9]. Families have for centuries been important elements of Iranian society. Families have been primary units for organizing nearly all of the social activities of life, including production, consumption, education, socialization, reproduction, leisure, and living arrangements. While family continues to remain a strong institution, a developmental ideal has changed the attitude

\footnotetext{
* Address correspondence to these authors at the Department of Sociology, Fayetteville State University, Fayetteville, NC 28301, United States; E-mail: aaghajanian@uncfsu.edu
} 
toward education, timing of marriage, and childbearing across generations. Specifically the forces of change has not only affected the younger generations extensively exposed to the modern values, but their parents and members of extended family who have been socialized by the traditional values of early marriage, procreation, and focus on domestic role for women. These cross-generational attitude changes have generated support from parents and members of the extended family for high female educational achievement in recent decades in Iran. Our analysis of census data regarding the school enrollment in Iran suggests a high level of striving for educational achievement by females that far exceeds that which would be expected and sanctioned by tradition.

\section{THE SETING}

Iran is a country in which over 99.6 percent of the population adheres to one of the sects of Islam, with the majority affiliated with the Shia sect. The population of Iran was about 30 million in 1976 and grew to about 50 million by 1986. Since then population growth has slowed; the latest decennial census showed a population of slightly above 70 million. Table 1 provides the distribution of the population by age and sex across four decades since 1976.

For a great part of the $20^{\text {th }}$ century, Iran lived under secular monarchs of the Pahlavi dynasty, with strong policies of modernization [10]. During the last four decades Iran has experienced some government sponsored urban oriented modernization under the monarchy regime of Pahlavi, the overthrow of the Pahlavi monarch and establishment of Islamic Republic; eight years of imposed war with Iraq with devastating human and infrastructure damages; a strong period of reconstruction leading to development of infrastructure for communication and access to satellite TV with international stations and spread of internet and wireless phones. As part of the reconstruction and development of infrastructure, the government has emphasized development and expansion of public educational institutions at all levels and strong support for creation of non-profit and for-profit educational institutions. Students accepted at public higher educational institutions not only do not pay any tuition but receive financial support through grants and loans. For those attending private institutions, the government facilitates loans and installment payment for all students.

The Islamic state has a constitution that is strongly influenced by Islamic rules and regulations, and those chosen as leaders of the government and the Parliament have been selected for and have shown strong religious leadership. There are a number of important advisory councils and assemblies made up largely of religious leaders who advise government agencies and create check and balance in establishing laws, policies and program [10].

Early in transition from a secular government to a religious state, the domestic role of women was addressedat national and local levels. Early marriage was emphasized, and charitable foundations were created to support young people needing resources for the marriage ceremony and for establishing a family. Highlighting the statement "heaven is under the step of mother," women were encouraged to stay home and take care of children, preparing them to be good Muslims. The best roles for women were "to be good mothers and wives." With such a clear rejection of Western values in relation to the role and position of women in the Iranian society, an extensive literature emerged concerning the declining status of women and the social destiny of females born into this new socio-political system [11 - 15]. Concern was expressed about declining opportunities for women's education, restrictions on women's pursuit of careers, and women's lack of power and authority within and outside of the household. It was thought that, through a return to traditional roles for women, the Iranian family would return to its traditional focus of preparing female children for a closed domestic world behind veils, and this would particularly mean a lack of emphasis on educational opportunities for females.

One particular concern of a number of authors has been the legal status of women in Iran in the $20^{\text {th }}$ century, especially since the establishment of the Islamic Republic [16 - 27]. Discussed with varying interpretations is that principles of Islam and the Shia tradition address women's legal status as being that of "a half witness" and include such tenets as "Sigheh or temporary marriage" and "men's unilateral right of divorce." While these legal issues can have effects on the educational attainment of females, the lack of relevant data makes it impossible to measure these effects at present. However, female educational attainment should provide some insight concerning female advancement in the presence of such views about the legalstatus of women. In this paper, our focus is on the education of females in Iran as measured in decennial censuses from 1976 to 2006 . Pecifically, we focus on gender difference in school enrollment from 1976, three years prior to the embellishment of the conservative Islamic government thus at a time when educational policies were governed by the Shah's secular government) to 2006, almost 30 years after the establishment of the Islamic government. 


\section{DATA AND METHOD}

The data for this study are drawn from national censuses conducted by the Statistical Center of Iran (SCI). The Center has conducted decennial censuses since 1956. The published tables from these censuses have been made available in print in the past and in multimedia format more recently. For this paper, tabulations of school enrollment by age groups are drawn from the four censuses. As noted, the 1976 census is associated with the time period in which the secular monarchy established policies about education for females, as well as for males. The 1986, 1996, and 2006 censuses reflect the political, social, and economic environment under the current Islamic Republic State. In the analysis of data regarding the education of females in Iran, we have provided a comparative context by viewing school enrollment of females relative to the enrollment of males in the same area and the same time period.

The measure of educational attainment and access used in this study is age-specific enrollment rate in pre-college education, and the enrollment rate of the age group 20-24 as a proxy measure for college enrollment. The rates presented here are slightly different from the rates calculated by the United Nations International Children's Emergency Fund (UNICEF). Since we are using published tabulated data, the age boundaries are slightly different from the age boundaries of different school levels. However, these difference are very minimal and do not affect our analysis of trends and differences across time, place, and gender. For the college enrollment rate we have used the educational enrollment rate of age group 20-24 for females and males. There is a possibility that the college enrollment rate is slightly overestimated by inclusion of a small number of those who are not enrolled in college. Again, for the purpose of this paper, particularly in relation to attendance of young women in schools and colleges, the slight overestimation does not change the interpretation of the data.

Table 1. Distribution of population by major age groups and sex, Iran 1986, 2006.

\begin{tabular}{|c|c|c|c|c|c|c|}
\hline & & 1986 & & & 2006 & \\
\hline & Male & Female & Total & Male & Female & Total \\
\hline & $\%$ & $\%$ & $\%$ & $\%$ & $\%$ & $\%$ \\
\hline Infants & 3.6 & 3.6 & 3.6 & 1.6 & 1.6 & 1.6 \\
\hline $1-5$ & 18.0 & 18.2 & 18.1 & 7.8 & 7.6 & 7.7 \\
\hline $6-10$ & 14.4 & 14.4 & 14.4 & 8.0 & 7.9 & 7.9 \\
\hline $11-14$ & 9.5 & 9.2 & 9.4 & 7.9 & 7.7 & 7.8 \\
\hline $15-24$ & 18.8 & 19.1 & 19.0 & 25.0 & 25.4 & 25.2 \\
\hline $25-64$ & 32.6 & 32.4 & 32.5 & 44.4 & 44.8 & 44.6 \\
\hline 65 and more & 3.0 & 3.0 & 3.0 & 5.4 & 5.0 & 5.2 \\
\hline Unknown & 0.1 & 0.0 & 0.0 & 0.0 & 0.0 & 0.0 \\
\hline Total & 100.0 & 100.0 & 100.0 & 100.0 & 100.0 & 100.0 \\
\hline Raw Total & $25,280,961$ & $24,164,049$ & $49,445,010$ & 35,866362 & $34,629,420$ & $70,495,782$ \\
\hline
\end{tabular}

\section{FINDINGS}

The overall pattern of significant increase in female school enrollment is presented in a snapshot in Fig. (1). In considering these rates, note that our focus is on two things: a comparison of rates for males and females and changes occurring over time in Iran. That is, we are not addressing comparisons of rates with those in other countries in the region or with western societies. Rather, our concern is with a comparison of educational rates for Iranian females relative to Iranian males at the same points in time and in the same localities (rural, urban) and experiencing the same economic and political situation existing in the country as a whole - although we recognize that there may be local variations in such factors, particularly considering the ethnic variation in Iran $[28,29]$.

The details of gender and rural-urban dynamics of change in school enrollment are presented in Table 1. The elementary school enrollment rate for girls in Iran was about 61 percent in 1976 as compared to $82.3 \%$ for boys; showing a gap of 20 percentage points. By 2006, this gap had decreased to less than one percentage points. In rural areas, the gender gap in elementary school enrollment decreased from 33 percentage points to less than three percentage points. 


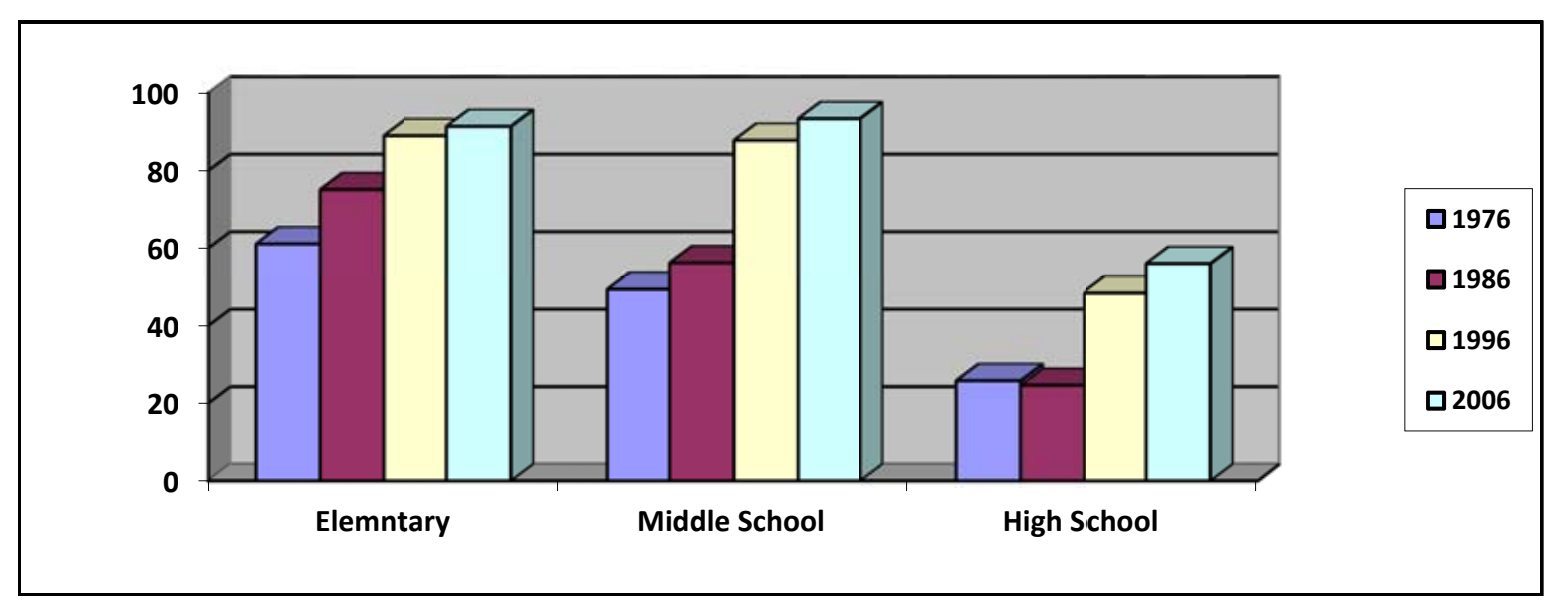

Fig. (1). Overall trend in increasing female school enrollment, 1976-2006.

Table 2. School enrollment rate of children in Iran by age and sex.

\begin{tabular}{|c|c|c|c|c|c|c|c|c|c|c|c|c|}
\hline & & All & & & & Urban & & & & Rural & & \\
\hline & \multicolumn{4}{|c|}{ Elementary Age Group } & \multicolumn{4}{|c|}{ Elementary Age Group } & \multicolumn{4}{|c|}{ Elementary Age Group } \\
\hline Sex & 1976 & 1986 & 1996 & 2006 & 1976 & 1986 & 1996 & 2006 & 1976 & 1986 & 1996 & 2006 \\
\hline Male & 82.3 & 87.6 & 93.0 & 92.0 & 92.1 & 93.5 & 95.3 & 93.0 & 74.6 & 82.3 & 90.7 & 88.9 \\
\hline Female & 61.0 & 75.1 & 89.0 & 91.4 & 85.5 & 89.7 & 94.0 & 92.2 & 41.7 & 61.5 & 84.1 & 86.1 \\
\hline \multirow[t]{2}{*}{ Difference } & 21.3 & 12.5 & 4.0 & 0.6 & 6.6 & 3.8 & 1.3 & 0.8 & 32.9 & 20.8 & 6.6 & 2.8 \\
\hline & \multicolumn{3}{|c|}{ Middle School Age Group } & & \multicolumn{3}{|c|}{ Middle School Age Group } & & \multicolumn{3}{|c|}{ Middle School Age Group } & \\
\hline Male & 76.0 & 77.5 & 91.7 & 94.7 & 90.2 & 86.5 & 94.7 & 94.5 & 61.8 & 68.8 & 85.5 & 86.8 \\
\hline Female & 49.4 & 56.2 & 87.8 & 93.4 & 77.4 & 77.0 & 93.4 & 94.2 & 23.4 & 35.7 & 68.1 & 76.6 \\
\hline \multirow[t]{2}{*}{ Difference } & 26.6 & 21.3 & 3.9 & 1.3 & 12.8 & 9.5 & 1.3 & 0.3 & 38.4 & 33.1 & 17.4 & 10.2 \\
\hline & \multicolumn{3}{|c|}{ High School Age Group } & & \multicolumn{3}{|c|}{ High School Age Group } & & \multicolumn{3}{|c|}{ High School Age Group } & \\
\hline Male & 47.5 & 40.2 & 55.3 & 57.0 & 63.6 & 51.1 & 64.5 & 63.5 & 25.4 & 10.3 & 41.7 & 44.4 \\
\hline Female & 25.8 & 24.6 & 48.4 & 56.0 & 45.0 & 37.1 & 62.7 & 65.0 & 6.7 & 2.7 & 27.2 & 37.3 \\
\hline Difference & 21.7 & 15.6 & 6.9 & 1.0 & 18.6 & 14.0 & 1.8 & -1.5 & 18.7 & 7.6 & 14.5 & 7.1 \\
\hline \multicolumn{5}{|c|}{ Source: [34 - 37] } & & & & & & & & \\
\hline
\end{tabular}

The decline in gender gap in enrollment rate for middle school and high school levels are much more impressive. For both males and females, school enrollment increased during the period under consideration; however, the increase in female enrollment was much higher leading to a significant reduction in the male-female enrollment differences. For middle school age group, the gap declined from 26.6 percentage points to less than two percentage points. In urban areas gender-gap in middle school enrollment declined from 12.8 to less than a fraction of percentage point. This decline loom much more considering the fact that 75 percent of the population lived in urban areas in 2006.

The third panel in Table 2 shows the high achievement of educational attainment of girls during this period at high school level. High school enrollment increased significantly for both girls and boy across rural and urban areas during the period 1976-2006. Again, the most important observation from this data is the declining gender-gap in enrollment. Overall the gender gap in high school enrollment declined from 22 percentage points in 1976 to one percentage points in 2006. In urban areas gender-gap reversed; suggesting more girls were enrolled in high school than boys. In rural areas, the high school enrollment increased significantly so that the gap between girls and boys declined from almost 19 percentage points to seven percentage points. It should be noted that these achievement happened despite the slowdown during the Iran-Iraq war period (1980-81).

Access to higher education in Iran has been and continues to be very competitive for both males and females. For a long period of time fewer than about 10 percent of applicants were admitted to the universities. The data presented in Table 3 show the estimates of college enrollment rate by age among females and males in urban and rural areas of Iran during the period 1976 through 2006. Again this data not only show significant increase in enrollment rate for both 
males and females in college age group, but impressive decline in the gap between males and females. While in 1976 female college enrollment is much less than male college enrollment by 2006, the female enrollment rate in college exceeds male enrollment rate by 3.2 percentage points. This achievement is observed both in urban and in rural areas.

Table 3. Enrollment rate of population 20-24 in Iran.

\begin{tabular}{|l|c|c|c|c|}
\hline & $\mathbf{1 9 7 6}$ & $\mathbf{1 9 8 6}$ & $\mathbf{1 9 9 6}$ & $\mathbf{2 0 0 6}$ \\
\hline Male & & Iran & & \\
\hline Female & 14.00 & 08.40 & 17.40 & 20.00 \\
\hline Difference & 6.30 & 04.70 & 14.00 & 23.20 \\
\hline & 7.7 & 3.7 & 3.4 & -3.2 \\
\hline Male & & Urban & 23.20 & 25.00 \\
\hline Female & 20.8 & 11.40 & 19.50 & 29.10 \\
\hline Difference & 11.30 & 06.40 & 3.7 & -4.1 \\
\hline & 9.5 & 5.0 & & 08.70 \\
\hline Male & 04.40 & 04.20 & 05.50 & 9.00 \\
\hline Female & 01.20 & 02.10 & 3.20 & 10.00 \\
\hline Difference & 3.20 & 2.10 & & -1.0 \\
\hline Source: [34-37]. & & & \\
\hline
\end{tabular}

From these data it is apparent that young women are breaking from tradition in seeking education. There seems to be strong support of parents for such educational achievements. Traditionally, the socio-cultural system of Iran encouraged parents to invest in their sons for their economic and social values. However, such bias has been fading in the context of exposure to new values and ideation of modernity. In addition, with the transition of the Iranian economy from a household-agricultural based economy where the labor of household members particularly female labor was vital for subsistence production, to a highly service oriented economy, not only there is need for less children but the improvement of the quality of both girls and boys has become essential for parents [30].

This educational achievement has been also facilitated by extraordinary expansion of public and private higher educational institutions and government support in expanding universities in small towns and rural areas. In the history of development of institutions of higher education in Iran since the establishment of the University of Tehran in 1935 , universities were located in large provincial capital cities. Even among these elite cities, prior to the 1980s a large number of the institutions of higher education were located in Tehran [31, 32]. As a result of this uneven distribution, very few eligible candidates from remote and poor areas in rural provinces were able to attend college. This geographically and economically biased pattern of higher educational resources, changed starting in 1980s. The government launched several initiatives and polices for expansion of both the number and wide geographic distribution of public and private educational institutions.

First, the medical college and other health related colleges were separated from regular universities. As a result, each province started its own medical school to train physicians and medical staff based on the provincial needs. Currently there are 30 provinces in Iran and each has at least one medical school supported by government. The second initiative was related to the establishment of at least one public university in each province. This increased access to higher education for those in rural provinces. Further, the government approved guidelines for the establishment of nonprofit universities. A pioneer nonprofit university system was established as early as 1984, under the organizational name of "Free Islamic University" - currently more popularly called the "Azad University System" - with hundreds of campuses across the country in small towns, rural areas, and underdeveloped provinces.

The more evenly expansion of institutions of higher education across the country has made social and physical access to higher education more accessible for both males and females. The estimates of number of higher educational institutions and their enrollment in 1976 and 2006 are presented in Table 4. Both these indicators point to the exponential growth in higher educational facilities and students facilitated by support from government through expansion of public universities, creation of policies and procedures for private sector investment in higher education, and financial support through grants and loans to a large number of students. 
Table 4. Number of higher education institutions and enrollment institutions fall 1976, fall 2006.

\begin{tabular}{|c|c|c|c|}
\hline Year & 1976 & 2006 & \% Change \\
\hline Estimated Number of higher Educational Institutions & 23 & 110 & +378.2 \\
\hline Estimated Enrollment in Higher Education & 107,400 & $1,938,874$ & +1705.3 \\
\hline
\end{tabular}

\section{DISCUSION AND CONCLUSION}

The findings in this paper suggest that a deterministic religious orientation with specific prescriptions about women's roles cannot easily explain the school enrollment and hence educational attainment of females in developing countries. When we looked at the data about Iran, we found that, despite all the rhetoric by government and religious leaders about the domestic roles of women school enrollment of females as compared to males has increased significantly both in urban and rural areas. There is no indication of any bias toward female educational enrollment, and at high school and university levels female enrollment has surpassed the enrollment of males. Furthermore, female educational enrollment has increased not only in urban areas but in remote rural towns and villages.

In approaching the data on female (as well as male) enrollment from primary through college levels, we believe that there is indeed a clear inconsistency between traditional views about women as wives and mothers and the pursuit of education and other non-traditional goals of females. We have attributed female striving and achievement of education, from primary through college levels, to the pervasion of the culture by what is called developmental idealism. This idealism is seen to enter - or it can even be said to invade - a traditional culture through media and other external influences, and to diffuse from youth across generations, resulting in goals that would seem inconsistent with traditional dictates. Among these goals is achieving education and what education may permit. It would seem inevitable that the individualism and self-actualization at the core of this idealism not only demands education and advancement beyond that education but feed and furthers the demand for individualism and self-actualization.

Such a progression, as it affects females as well as males, might seem antithetical to the Islamic faith that continues to dominate the Iranian culture. Indeed, it might be expected that religious leaders might make it impossible for educational advances to occur. It is clear that they have not done so, but instead have in fact expanded both the number and wide geographic distribution of public and private educational institutions. An observer might question the seeming disconnect between religious teaching about the role of women and the provision of educational opportunities for women as well as for men. There are two reasons why this is likely only a seeming inconsistency. First, inherent in Islamic religious tenets is the dictum that people have a duty to be educated, and there is no specific statement limiting education to men. Second, providing education for all citizens, women as well as men, is likely a pragmatic decision, based on the obvious need for an educated citizenry to advance Iranian technology and influence in the larger world scene.

In this report, we have focused only on Iran, offering evidence that educational advancement has taken place for women, as well as men, in a culture dominated by Islamic religion and values. While here and elsewhere [33], we have noted other socio-cultural changes in women's achievements and roles, we have not attempted here to argue that formal education has been solely responsible for changes in such things as reproduction and family size or in other sociocultural behaviors and values. Nor have we have attempted to compare our findings with findings from other Islamic cultures, and have therefore not argued that Iran is in fact unique. Other Islamic cultures could well be following patterns similar to those seen in Iran. It is very important to examine how other cultures in other Islamic countries in the Middle East and in other regions, have moved toward pragmatic policies about education, including for women. Such studies might demonstrate similar shifts in other socio-cultural values that pertain to women.

\section{CONFLICT OF INTEREST}

The authors confirm that this article content has no conflict of interest.

\section{ACKNOWLEDGEMENTS}

We are thankful to the anonymous reviewers for their careful reading and suggestion for this manuscript. 


\section{REFRENCES}

[1] Abbasi-Shavazi. The fertility transition in Iran: Revolution and reproduction. Springer 2009.

[2] Kirk D. Factors affecting Moslem natality. In: Nam C, Ed. Population and Society: A textbook of readings. New York, Houghton 1965; pp. $230-43$.

[3] Caldwell JC. Routes to low mortality in poor countries. Popul Dev Rev 1986; 12(2): 171-220. [http://dx.doi.org/10.2307/1973108]

[4] Cherif FM. Culture, rights, and norms: Women's rights reform in Muslim countries. J Polit 2010; 72(4): 1144-60. [http://dx.doi.org/10.1017/S0022381610000587]

[5] Sechzer JA. Islam and woman: Where tradition meets modernity: History and interpretations of Islamic women's status. Sex Roles 2004; 51(5-6): 263-72.

[http://dx.doi.org/10.1023/B:SERS.0000046610.16101.e0]

[6] Thomas GM, John WM, Francisco OR, John B. Institutional structure: Constituting state, society, and the individual. Newbury Park: CA: Sage 1987.

[7] Meyer JW, Boli J, Thomas GM, Ramirez FO. World society and the nation-state. Am J Sociol 1997; $103(1)$ : $144-81$. [http://dx.doi.org/10.1086/231174]

[8] Thornton A. The developmental paradigm, reading history sideways, and family myths. Ann Arbor 2005; 1-32. Available from: http:// developmentalidealism.org/pubs/docs/thornton_RobertMalthusWorkingPaper.pdf

[9] Abbasi-Shavazi MJ, Jalal M, Askari-Nodoushan A. Family life and developmental idealism in Yazd, Iran. Demogr Res 2012; 26: 207-38. [http://dx.doi.org/10.4054/DemRes.2012.26.10] [PMID: 22942772]

[10] Abrahamian E. A history of modern Iran. Cambridge University Press 2008. [http://dx.doi.org/10.1017/CBO9780511984402]

[11] Esfandiari H. Reconstructed lives: women and Iran's Islamic revolution. Woodrow Wilson Center Press 1997.

[12] Nashat G. Women in the Islamic Republic of Iran. Iran Stud 1980; 13(1-4): 165-94. [http://dx.doi.org/10.1080/00210868008701569]

[13] Nashat G. The women's struggle in Iran. Mon Rev 1981; 32(1): 22-30.

[14] Tabari A. The enigma of veiled Iranian women. Fem Rev 1980; 5(1): 19-31. [http://dx.doi.org/10.1057/fr.1980.10]

[15] Zolan AJ. Effect of Islamization on the legal and social status of women in Iran. The BC Third World LJ 1987; 7: 183.

[16] Afary J. Sexual politics in modern Iran. Cambridge University Press 2009. [http://dx.doi.org/10.1017/CBO9780511815249]

[17] Haeri S. Law of desire: Temporary marriage in Shi'i Iran. Syracuse University Press 2014

[18] Haeri S. Temporary marriage and the state in Iran: An Islamic discourse on female sexuality. Soc Res (New York) 1992; 201-23.

[19] Higgins PJ. Women in the Islamic Republic of Iran: Legal, social, and ideological changes. Signs (Chic Ill) 1985; 10(3): 477-94. [http://dx.doi.org/10.1086/494156]

[20] Hoodfar H. Iranian women at the intersection of citizenship and the family code. In: Gender and citizenship in the Middle East. 2000; pp. 287-313.

[21] Mir-Hosseini Z. Women, marriage and the law in post-revolutionary Iran. In: Women in the Middle East. Palgrave Macmillan UK 1993; pp. 59-84.

[http://dx.doi.org/10.1007/978-1-349-22588-0_3]

[22] Mir-Hosseini Z. Marriage on trial In: A study of Islamic family law. IB Tauris 2000.

[23] Mir-Hosseini Z. The politics and hermeneutics of hijab in Iran: From confinement to choice. Muslim World J of Human Rights 2007; 4(1): 1554-4419. [Published online]. [http://dx.doi.org/10.2202/1554-4419.1114]

[24] Mir-Hosseini Z. How the door of ijtihad was opened and closed: a comparative analysis of recent family law reforms in Iran and Morocco. Wash Lee Law Rev 2007; 64: 1499.

[25] Najmabadi A. Women with mustaches and Men without beards. Gender and Sexual Anxieties of Iranian Modernity 2005.

[26] Shaditalab J. Islamization and gender in Iran: Is the glass half full or half empty? Signs (Chic Ill) 2006; 32(1): 14-21. [http://dx.doi.org/10.1086/505276]

[27] Williams JA. Unholy matrimony? Feminism, orientalism, and the possibility of double critique. Signs (Chic Ill) 2009; 34(3): 611-32. [http://dx.doi.org/10.1086/593354]

[28] Amanolahi S. A note on ethnicity and ethnic groups in Iran. Iran \& the Caucasus 2005; 37-41. [http://dx.doi.org/10.1163/1573384054068105] 
[29] Torabi F, Baschieri A. Ethnic differences in transition to first marriage in Iran: the role of marriage market, women's socio-economic status, and process of development. Demogr Res 2010; 22: 29.

[http://dx.doi.org/10.4054/DemRes.2010.22.2]

[30] Jalal Abbasi-Shavazi M, McDonald P, Hosseini-Chavoshi M. Modernization or cultural maintenance: the practice of consanguineous marriage in Iran. J Biosoc Sci 2008; 40(6): 911-33. [http://dx.doi.org/10.1017/S0021932008002782] [PMID: 18346301]

[31] Banani A. The modernization of Iran, 1921-1941. Stanford University Press 1961.

[32] Menashri D. Education and the Making of Modern Iran. Ithaca, NY: Cornell University Press 1992.

[33] Aghajanian A, Tashakkori A, Thompson V, Mehryar AH, Kazemipour S. Attitudes of Iranian female adolescents toward education and nonfamilial roles: A study of a postrevolutionary cohort. Marriage Fam Rev 2007; 42(1): 49-64. [http://dx.doi.org/10.1300/J002v42n01_04]

[34] Report of the 1986 Census of Housing and Population of Iran. Tehran, Iran: Iran Statistical Center 1990.

[35] Report of the 2006 Census of Housing and Population of Iran. Tehran, Iran: Iran Statistical Center 2008.

[36] Report of the 1976 Census of Housing and Population of Iran. Tehran, Iran: Iran Statistical Center 1980.

[37] Report of the 1996 Census of Housing and Population of Iran. Tehran, Iran: Iran Statistical Center 2000.

[38] Statistical Year Book of Iran, 1979. Tehran, Iran: Iran Statistical Center 1980.

[39] Statistical Year Book of Iran, 2006-2007. Tehran, Iran: Iran Statistical Center 2007.

(C) Aghajanian et al.; Licensee Bentham Open.

This is an open access article licensed under the terms of the Creative Commons Attribution-Non-Commercial 4.0 International Public License (CC BY-NC 4.0) (https://creativecommons.org/licenses/by-nc/4.0/legalcode), which permits unrestricted, non-commercial use, distribution and reproduction in any medium, provided the work is properly cited. 